\title{
DETERMINATION OF SENSITIVITY AND SPECIFICITY OF ULTRASONOGRAPHY IN ACUTE APPENDICITIS: COMPARISON WITH PER-OPERATIVE FINDINGS AND HISTOPATHOLOGICAL REPORT
}

\author{
SASMITA PARIDA, BIBEKANANDA NAYAK, JAYASHREE MOHANTY
}

Department of Radio Diagnosis, SCB Medical College, Cuttack, Orissa, India. Email: drparidasasmita@gmail.com Received: 03 April 2017, Revised and Accepted: 24 May 2017

\section{ABSTRACT}

Objective: This study was under taken to compare the ultrasonographic findings with pre-operative findings and histo-pathological report and to evaluate the sensitivity, specificity, positive and negative predictive values and accuracy of ultrasonography in the diagnosis of acute appendicitis.

Methods: It was a prospective study done in the department of radio-diagnosis, SCBMCH, Cuttack. Patients with provisional diagnosis of acute appendicitis were subjected to ultrasound of abdomen and pelvis. Patients with positive USG findings were followed up for pre-operative findings and histo-pathological results. All the obtained data were tabulated and subjected to statistical analysis.

Results: Among the 100 cases studied, 77 cases were proved as acute appendicitis based on surgical and histopathological results. Male to female ratio was 1.5:1. The disease was found to be more prevalent in second and third decade of life. Location of affected appendix was most commonly retro caecal. Mean diameter of the appendix was $8.56 \mathrm{~mm}$. Target sign and non-compressible bowel loop was the most commonly detected ultrasonographic sign and the ultrasonographic sensitivity was $96.1 \%$ and specificity was $95.65 \%$ in our study.

Conclusion: High resolution sonography with graded compression is a very useful diagnostic tool for diagnosis of appendicitis in problematic cases and in women in their reproductive period. It is also helpful in detecting complications of appendicitis and other abdominal diseases that mimic acute appendicitis.

Keywords: Acute appendicitis, Appendicolith, Ultrasonography, Appendectomy.

(C) 2017 The Authors. Published by Innovare Academic Sciences Pvt Ltd. This is an open access article under the CC BY license (http://creativecommons. org/licenses/by/4. 0/) DOI: http://dx.doi.org/10.22159/ajpcr.2017.v10i9.18873

\section{INTRODUCTION}

Acute appendicitis is one of the most common surgical abdominal emergencies in India. Any delay in the diagnosis increases the morbidity period, undue complications, and mortality rate. As this disease is amenable for treatment by surgery, early diagnosis plays an important role in the early treatment and in preventing undue complications [1].

Acute appendicitis is one of the most common causes of acute abdomen in young adults. Acute appendicitis is relatively rare in infants, becoming increasingly common in childhood and early adult life, reaching a peak incidence in teens and early 20 's. In about $30 \%$ of patients, the signs, symptoms, and laboratory findings of acute appendicitis are atypical often leading to delay in diagnosis and surgical intervention with consequent increase in rate of perforation and complication.

In addition, other diseases produce clinical and laboratory findings similar to that of acute appendicitis leading to negative appendectomy rate of $20-25 \%$. This rate is as high as $30-35 \%$ in case of female patients in their reproductive years because of various gynecological diseases.

Grades compression ultrasound using high-frequency linear array transducers in supine position for diagnosing acute appendicitis was advocated by Puylaert et al. [2].

Ultrasound can diagnose a number of conditions that mimic appendicitis clinically. If appendicitis can be excluded sonologically and an alternative diagnosis can be made, two benefits will occur. Unnecessary appendectomy can be avoided and appropriate treatment can be instituted. Ultrasound can be recommend in children when there is diagnostic doubt, in young women (due to high incidence of tubal disease), and in patients who are pregnant [3]
Women, in particular, benefit most from preoperative imaging, with a statistically significant lower negative appendectomy rate than that in women who undergo no preoperative imaging.

The use of high-frequency probes gives better lateral and axial resolution. Higher-frequencies are absorbed more strongly so depth resolution is less. Therefore, both probes are needed to examine the patients. In conjunction with pre-operative findings and histopathological (HP) results, it provides useful information for accurate diagnosis and treatment for the patient.

The aim of this present study was to find out the sensitivity and specificity of ultrasonography (USG) in acute appendicitis, to study the positive and negative predictive values and accuracy of ultrasound in the diagnosis of acute appendicitis and also to compare the USG findings with pre-operative findings and HP reports.

\section{METHODS}

This is a prospective study done in the Department of Radiodiagnosis in SCB Medical College Hospital (MCH), Cuttack during September 2013 to September 2015

A total number of 100 cases referred to the Department of Radiodiagnosis, SCB MCH, Cuttack with the clinical diagnosis of acute appendicitis were taken for the study. Institutional ethical clearance and informed consent from patients were obtained before the study after recording the proper history, clinical examination, and relevant laboratory investigation; patients were subjected to USG examination. Patients were followed up for pre-operative and HP findings. Obtained data were tabulated and percentages were taken. From these data sensitivity, specificity, positive and negative values 
of ultrasound, and accuracy of ultrasound in acute appendicitis were calculated.

\section{Inclusion criteria}

All the patients with clinical and laboratory diagnosis of acute appendicitis were included in the study.

\section{Exclusion criteria}

Patients who were unfit for the surgery, cases with appendicular lump, cases with peritonitis, and recurrent appendicitis were excluded from the study. Patients more than 75 years of age and uncooperative patients were also excluded from the study.

\section{Ultrasound protocol}

First, general survey of the patient's abdomen was performed with 2-5 $\mathrm{MHz}$ curvilinear probe; then, the examination of the right lower quadrant by graded compression technique with $3-12 \mathrm{MHz}$ linear probe was done.

Scanning was done in the supine position while applying gradual compression, which displaces the shadowing gas contents in the caecum and ascending colon allowing visualization of the retrocaecal area. It also brings the intra-abdominal structures closer to the transducer and its focal zone. Scanning was performed in a routine fashion in the transverse plane starting from the point below the tip of the caecum and moving cephalad to the middle of the transverse colon. Examination in the longitudinal plane was used to confirm the findings.

The inflamed appendix was usually located just near medial and inferior to the caecum and anterior and lateral to the iliac vessels, occasionally posterior to the caecum. If the appendix was not located, scanning the area where the patient shows maximum tenderness by fingertip was usually the site of appendix. After visualization of the appendix (non-compressible bowel loop), the diameter of the appendix was measured and appendicolith, collection of fluid in the right iliac fossa, echogenic and thickened mesentry, and caecal wall thickening were looked for

\section{RESULTS}

The study was done in 100 clinically diagnosed patients with acute appendicitis (Fig. 1). In our study, age of the patient varied from 2 to 67 years and maximum number of patients were in the age group of 11-20 years $(41.7 \%)$ (Table 1$)$. The male to female ratio was 1.5:1. In present study, $98.7 \%$ cases were having pain in the abdomen followed by tenderness $(93.5 \%)$, nausea and vomiting in $66 \%$, and fever in $66 \%$ of cases (Table 2).

Among the 100 cases studied, 77 cases were proved surgically and histopathologically as acute appendicitis (Table 3) (in USG 75 cases were diagnosed as acute appendicitis), 4 cases were appendicular mass, 4 cases were pelvic inflammatory disease, 3 cases were right ureteric calculus, 2 cases were ileocaecal tuberoculosis, 2 cases were right acute pyelonephritis, 1 case was twisted ovarian cyst, 1 case was ileitis, 1 case was carcinoma caecum, and no abnormality was detected in 5 cases (Table 4, Figs. 1 and 2).

Table 1: Age incidence of acute appendicitis and appendicular mass in ultrasound diagnosis

\begin{tabular}{ll}
\hline Age (years) & No. of patients (\%) \\
\hline $0-10$ & $12(15.18)$ \\
$11-20$ & $33(41.77)$ \\
$21-30$ & $17(21.51)$ \\
$31-40$ & $5(6.32)$ \\
$41-50$ & $7(8.86)$ \\
$51-60$ & $3(3.78)$ \\
$61-70$ & $2(2.53)$ \\
Total & $79(100)$ \\
\hline
\end{tabular}

Retrocaecal appendix was observed in 59 cases $(76.62 \%)$ of total cases, pelvic in 13 cases (16.88\%), subcaecal in 2 cases (2.59\%), and per illeal in 1 case $(1.29 \%)$ (Table 5$)$.

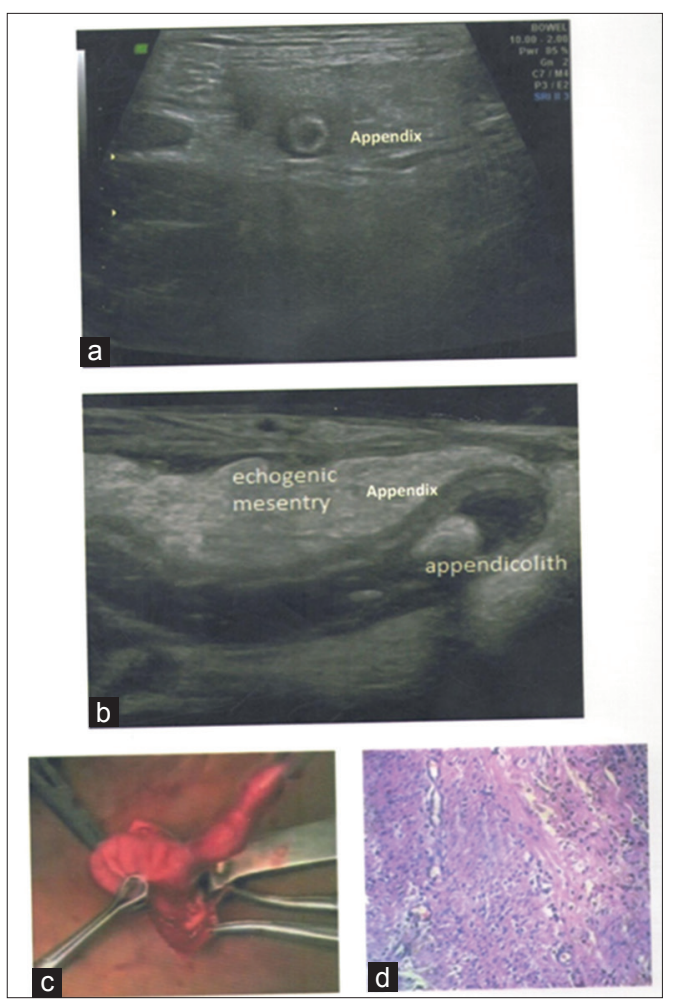

Fig. 1: Acute appendicitis with appendicolith. (a) Transverse, (b) longitudinal, (c) per-operarive, (d) histopatholical

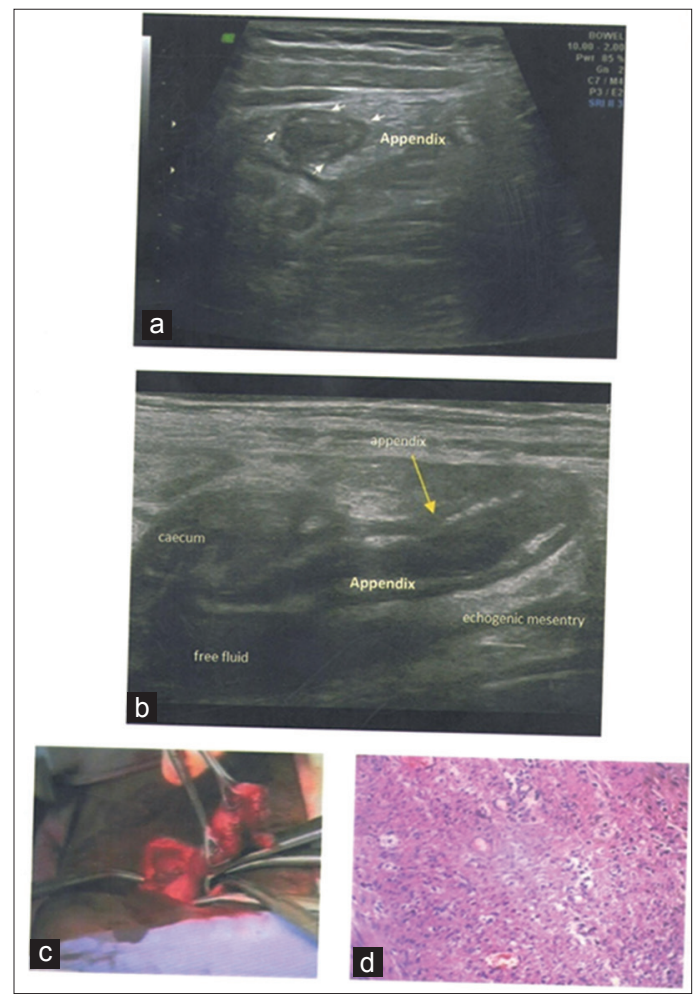

Fig. 2: Acute and chronic appendicitis with caecal wall thickening and free fluid in right iliac fossa. (a) Transverse, (b) longitudinal, (c) per-operarive, (d) histopatholical 
In our study, 98.7\% cases were found with target sign. 93.5\% cases showed probe tenderness, $35 \%$ cases showed fluid in right illaec fossa, $12.9 \%$ cases showed appendicolith, and $83 \%$ cases with echogenic mesentry in cases of acute appendicitis, 100\% cases showed diameter more than $6 \mathrm{~mm}, 25.9 \%$ cases showed caecal wall thickening and $96.1 \%$ cases showed non-compressible bowel loop (Tables 6 and 7).

\section{DISCUSSION}

USG examination of acute appendicitis is the most commonly used imaging technique. The medical ultrasound is in use since middle 1950 's, there is an increase in the clinical value in diagnosis of acute

Table 2: Clinical findings in cases of acute appendicitis

\begin{tabular}{ll}
\hline Clinical findings (signs and symptoms) & No. of cases (\%) \\
\hline Pain abdomen & $76(98.7)$ \\
Tenderness & $72(93.5)$ \\
Fever & $51(66)$ \\
Nausea and vomiting & $51(66)$ \\
\hline
\end{tabular}

Table 3: Acute appendicitis in USG/per-OP/HP study

No. of case diagnosed acute appendicitis in USG

No. of cases diagnosed in per-operative study 77

No. of cases diagnosed in HP study

USG: Ultrasonography, HP: Histopathological

Table 4: The spectrum of disease which mimics acute appendicitis in ultrasound in our cases

\begin{tabular}{llll}
\hline Disease & Male & Female & Total \\
\hline Acute appendicitis & 45 & 30 & 75 \\
Appendicular mass & 3 & 1 & 4 \\
Right acute pyelonephritis & - & 2 & 2 \\
Right ureteric calculus & 3 & - & 3 \\
Pelvic inflammatory disease & - & 4 & 4 \\
Twisted ovarian cyst & - & 1 & 1 \\
Ileitis & 0 & - & 0 \\
Ileocaecal tuberculosis & 1 & 1 & 2 \\
Carcinoma caecum & 1 & - & 1 \\
No abnormality detected & 4 & 4 & 8 \\
Total & 57 & 43 & 100 \\
\hline
\end{tabular}

Table 5: Position of appendix in our series

\begin{tabular}{ll}
\hline Appendix position & No. of cases (\%) \\
\hline Retro caecal & $59(76.62)$ \\
Pelvic & $13(16.88)$ \\
Subcaecal & $2(2.59)$ \\
Pre-ileal & $1(1.29)$ \\
Post-ileal & $1(1.29)$ \\
Subhepatic & $1(1.29)$ \\
Total & $77(100)$ \\
\hline
\end{tabular}

Table 6: Sonographic findings in case of acute appendicitis and percentage

\begin{tabular}{ll}
\hline Findings & No. of cases (\%) \\
\hline Target sign & $76(98.7)$ \\
Probe tenderness & $72(93.5)$ \\
Free fluid & $27(35)$ \\
Thickened or echogenic mesentery & $64(83)$ \\
Non-compressible bowel loop & $74(96.1)$ \\
Caecal wall thickening & $20(25.9)$ \\
Appendicolith & $10(12.9)$ \\
\hline
\end{tabular}

appendicitis due to evolution of graded compression technique by Puylaert in 1986 [2].

For patients with right left quadrant (RLQ) pain, the question has to be answered whether the pain is really due to acute appendicitis or other diseases which mimic acute appendicitis.

The clinical presentation of acute appendicitis is typical in than $70 \%$ of patients. About $30 \%$ of patients have an uncertain preoperative diagnosis.

Consequently, the rate of unnecessary laparotomy for acute appendicitis is as high as $20-25 \%$. The rate is even higher $35-45 \%$ in women of child-bearing age group because of pelvic inflammatory disease and complicated pregnancies. Hence, USG examination of the right left quadrant is necessary for these patients [4].

According to a study done by Jeffery Jr. et al. the mean age group for the occurrence of appendicitis was 26 years and according to Galindo Lallego the mean age group was 21.8 years [5]. Among 100 cases studied $41.7 \%$ of cases were in the age group of 11-20 years followed by age group of 20-30 years.

In our study, of 75 cases of acute appendicitis, 45 patients were male and 30 patients were female. The male to female ratio was 1.5:1. According to Bailey and Love textbook of surgery, males were more commonly affected than females.

In our study, it was found that $98.7 \%$ of cases were having pain in abdomen, 93.5\% cases showed tenderness, 66\% cases were with nausea and vomiting, and $66 \%$ cases were with fever

According to Jeffery et al., abdominal pain was found in $99-100 \%$ of cases, tenderness in right lower quadrant was found in $96 \%$ of cases, nausea and vomiting in $60-90 \%$ of cases, low-grade fever in $67-69 \%$ of cases, which is correlating with the study [5]

In the present study, $98.7 \%$ cases were found with target sign, $93.5 \%$ cases showed probe tenderness, $35 \%$ cases showed fluid in right illaec fossa, $2.9 \%$ cases showed appendicolith, and $83 \%$ cases were with echogenic mesentery in cases of acute appendicitis.

According to Subash et al., percentage of target sign was $98.7 \%$, probe tenderness was $100 \%$, fluid in right illaec fossa was $35 \%$, appendicolith in $9 \%$ cases, and echogenic mesentery was $80.9 \%$ which was correlating with this study [6].

In our study, 96.1\% cases showed appendix diameter more than $6 \mathrm{~mm}$, $25.9 \%$ cases showed caecal wail thickening, $96.1 \%$ cases showed noncompressible bowel loop, and $83 \%$ cases showed echogenic fat.

According to Hussain et al. the diameter of appendix on ultrasound was more than $6 \mathrm{~mm}$ in $96.7 \%$ cases. Non-compressible bowel loop was found in $93.3 \%$ cases, echogenic fat in $86.7 \%$ cases, and caecal thickening in $20 \%$ cases. This finding was highly correlating with our study [7].

In our study, we observed retrocaecal appendix in 59 cases (76.62\%) of total cases, pelvic in 13 cases (16.88\%), subcaecal in 2 cases $(2.59 \%)$,

Table 7: Calculation of sensitivity, specificity, positive, and negative predictive value

\begin{tabular}{lll}
\hline $\begin{array}{l}\text { Sonographic diagnosis } \\
\text { disease }\end{array}$ & $\begin{array}{l}\text { Patients with } \\
\text { disease }\end{array}$ & Patients without \\
\hline Positive & $74(\mathrm{a})$ & $1(\mathrm{~b})$ \\
Negative & $3(\mathrm{c})$ & $22(\mathrm{~d})$ \\
Sensitivity & $\mathrm{a} / \mathrm{a}+\mathrm{c} \times 100$ & $96.1 \%$ \\
Specificity & $\mathrm{d} / \mathrm{d}+\mathrm{c} \times 100$ & $95.65 \%$ \\
Positive predictive value & $\mathrm{a} / \mathrm{a}+\mathrm{b} \times 100$ & $98.66 \%$ \\
Negative predictive value & $\mathrm{d} / \mathrm{d}+\mathrm{c} \times 100$ & $88 \%$ \\
\hline
\end{tabular}


preileal in I case (1.29\%), postileal in I case (1.29\%), and subhepatic in 1 case $(1.29 \%)$.

According to Walker et al., the appendix was retrocaecal and retrocolic in $65.28 \%$, pelvic in $31.01 \%$, subcaecal in $2.26 \%$, preileal in $1 \%$, and postileal in $0.4 \%$ [8].

In our study, we had taken the maximum outer diameter of the normal appendix $6 \mathrm{~mm}$ as a sonographic criterion. Mean diameter of appendix in our study was $8.56 \mathrm{~mm}$.

Abu-Yousef et al. in their study had taken the maximum outer diameter of normal appendix was $6 \mathrm{~mm}$ as a sonographic criterion [9]. Furthermore, Jeffrey Jr et al. in their study took maximum outer diameter of $6 \mathrm{~mm}$ as a sonographic criterion for acute appendicitis while mean diameter of their study was $8.7 \mathrm{~mm}[5]$.

In our study, role of USG in diagnosis of acute appendicitis the sensitivity was $96.1 \%$. According to Jeffrey Jr. et al. study sensitivity was $89.9 \%$. According to Joshi et al., the sensitivity was $96 \%$. In our study, the sensitivity was correlating with the above-reported series [10]

We found the role of USG in diagnosis of acute appendicitis specificity was $95.65 \%$.

Jeffrey Jr. et al. reported the specificity to be $96.2 \%$, Joshi et al. reported specificity to be $93 \%$, and Puylaert et al. reported $100 \%$ specificity. The specificity in our series was correlating with the above-reported series $[10,2]$.

In our study, false negativity of $3 \%$ was noted. These patients were obese with thick abdominal wall, so we could not locate the appendix. These were proved to be retrocaecal and subhepatic appendix at surgery. In a study by Joshi et al., false negativity of $4 \%$ was reported [10].

In our study, false positivity of $1 \%$ was noted. Ileitis of terminal ileum was mistaken as an inflamed appendix. Josi et al. also reported a false positivity of $2 \%$. An inflamed Meckel's diverticulum was mistaken as an inflamed appendix in their patients [10]

In our study, role of USG in the diagnosis of acute appendicitis predictive value of positive test was $98.66 \%$ which was similar to the findings of Jeffrey Jr et al. as $93 \%$ and Joshi et al. as $98 \%[5,10]$.

In our study, role of USG in the diagnosis of acute appendicitis predictive value of negative test was $88 \%$. In a study by Jeffrey Jr. et al., it was reported as $94.3 \%$ [5]. Joshi et al. reported it was $88 \%$ which was similar to our study [10].

Role of USG in diagnosis of diseases mimicking acute appendicitis In a review by Gaensler et al., [11] USG was found to be 70\%. An accurate in detecting non-appendiceal disease in a group of patients without appendicitis in whom a specific diagnosis was made; however, half of their patients without appendicitis had a nonspecific diagnosis of abdominal pain of known origin. USG was helpful in the diagnosis of various gynecologic and visceral diseases but was less accurate in the diagnosis of urinary tract disease.

Early and accurate diagnosis of appendicitis is important, both to lower the negative appendectomy rate and to avoid increased risk of perforation associated with operative delay. If perforation occurs operative morbidity increases 15 -fold, and mortality increases 50 fold.

Many diseases mimic acute appendicitis in their clinical presentation, including those seen only in women of child-bearing age, such as pelvic inflammatory disease, torsion of ovarian cysts or tumors, endometriosis, hemorrhagic corpus luteal cysts, and hemorrhagic or necrotic uterine fibroids.
In pregnant women, conditions such as ectopic pregnancy, placental abruption, and uterine wall rupture can clinically resemble acute appendicitis. Conditions such as acute cholecystitis, diverticulitis, intestinal obstruction, renal stones and perforated gastric, or duodenal ulcers can pose diagnostic problems in both sexes. USG is also helpful in the diagnosis of Campylobacter ileocolitis and other forms of ileocolitis that can mimic acute appendicitis in their presentation.

USG shows mural thickening of the terminal ileum and proximal colon as well as moderately enlarged mesenteric lymph nodes [12]. Surgical intervention is not indicated in this disease.

In immunocompromised patients, neutropenictyphlitis can present with RLQ pain and fever without leukocytosis. USG can be helpful in differentiating this condition from acute appendicitis as hypoechoic or echogenic thickening of the wall of the caecum and ascending colon is seen [13].

"USG is also helpful in the diagnosis of mesenteric adenitis, another condition that can have a similar presentation to that of acute appendicitis." The inflammatory process is self-limiting, and laparotomy is not indicated $[14,15]$.

\section{RECOMMENDATIONS}

Patients with suspected acute appendicitis can be divided into four groups. Patients with typical clinical and laboratory findings of acute appendicitis constituting the first group should undergo laparotomy without delay. USG will not increase the accuracy of clinical diagnosis, in these cases and may cause false sense of security with detrimental results because of false negative results.

Patients with atypical clinical diagnosis and most ovulating women should have high-resolution USG evaluation of the RLQ. Those with a sonographic diagnosis of acute appendicitis, constituting the second group, should be considered for surgery regardless of their clinical symptoms, as a false positive rate of sonography is low. With this approach, the diagnosis of acute appendicitis may be made promptly, thus preventing or decreasing the risk of perforation and hence the morbidity and mortality of acute appendicitis.

The third group consists of those with atypical clinical symptoms and adequate negative sonographic examinations. The negative examination is conclusive if the intraperitoneal structures, such as caecum, terminal ileum, psoas muscles, and ileal vessels are visualized, and if gas can be displaced from the colon so that the retrocaecal area may be adequately demonstrated. If the sonographic examination of the pelvis and abdomen is not revealing, this third group can be observed clinically until there is resolution of symptoms and signs and return of laboratory findings to normal values.

The fourth group consists of those with negative, but technically inadequate, USG examinations. Depending on the degree of clinical suspicion, these patients should be operated on, evaluated by other imaging studies such as computed tomography (CT), or followed clinically.

In both third and fourth groups, the pelvic or abdominal USG may reveal other diseases, and the clinician is then directed to a different course of treatment.

\section{CONCLUSION}

We suggest patients with acute appendicitis can be divided into three groups.

1. Patients with typical clinical, laboratory, and ultrasound findings should undergo laparotomy without any delay.

2. Patients with atypical clinical diagnosis but positive sonographic diagnosis should also be considered for surgery regardless of their clinical symptoms as false positive rate of sonography is low. 
3. Patients with atypical clinical symptoms but adequate negative sonographic examination should be observed clinically or evaluated but other imaging modalities such as CT. In these cases, appendicitis mimics may play a role in diagnosis.

Hence, high-resolution sonography with graded compression is a very promising examination for the diagnosis of appendicitis in complicated cases and women in their reproductive period. It is fast and easy to perform. Because of its high accuracy, sonography should be the primary imaging procedure for patients suspected to have acute appendicitis. Ultrasound is also helpful in detecting complications of appendicitis and for other abdominal diseases that mimic appendicitis.

\section{REFERENCES}

1. Javidi Parsijani P, Pourhabibi Zarandi N, Paydar S, Abbasi HR, Bolandparvaz S. Accuracy of ultrasonography in diagnosing acute appendicitis. Bull Emerg Trauma 2013;1(4):158-63.

2. Puylaert JB. Acute appendicitis: US evaluation using graded compression. Radiology 1986;158(2):355-60.

3. Khan SA, Gafur MA, Islam A, Rahman MS. Correlation between clinical presentation, peroperative finding and histopathological report in acute appendicitis. Mymensingh Med J 2011;20(4):570-7.

4. Pittman-Waller VA, Myers JG, Stewart RM, Dent DL, Page CP, Gray GA, et al. Appendicitis: Why so complicated? Analysis of 5755 consecutive appendectomies. Am Surg 2000;66(6):548-54.

5. Jeffrey RB, Jain KA, Nghiem HV. Sonographic diagnosis of acute appendicitis: Interpretive pitfalls. AJR Am J Roentgenol 1994;162(1):55-9.
6. Subash KC, De A, Pathak M, Sathian B. Diagnostic role of ultrasonography in acute appendicitis: A study at a tertiary care hospital. Am J Public Health Res 2015;3(5):23-8.

7. Hussain S, Rahman A, Abbasi T, Aziz T. Diagnostic acuuracy of ultrasonography in acute appendicitis. J Ayub Med Coll Abbottabad 2014;26(1):12-7.

8. Walker AR, Walker BF, Duvehage A, Jones J, Ncongwane J, Segal I. Appendicectomy prevalences in South African blacks. Digestion $1982 ; 23: 274-8$

9. Abu-Yousef MM, Bleicher JJ, Maher JW, Urdaneta LF, Franken EA Jr, Metcalf AM, et al. High-resolution sonography of acute appendicitis. Am J Roentgenol 1987;149:53-8.

10. Joshi HM, Patel VB, Dave AN. Ultrasonographic Evaluation of acute appendicitis. Indian J Radiol Imaging 1996;2:75-8.

11. Gaensler R, Erik HL, Jeffrey B Jr, Laing FC, Townsend RR. Sonography in patients with suspected acute appendicitis: Value in establishing alternative diagnoses. Am J Roentgenol 1989;152:49-51.

12. Kessler N, Cyteval C, Gallix B, Lesnik A, Blayac PM, Pujol J, et al. Appendicitis: Evaluation of sensitivity, specificity, and predictive values of US, Doppler US, and laboratory findings. Radiology 2004;230(2):472-8.

13. Lee JH, Jeong YK, Park KB, Park JK, Jeong AK, Hwang JC. Operatordependent techniques for graded compression sonography to detect the appendix and diagnose acute appendicitis. AJR Am J Roentgenol 2005;184(1):91-7.

14. Nagapuri S. Market research on usage of antibiotics in serious infections. Int J Pharm Pharm Sci 2014;6(7):371-4

15. Sodimbaku V, Pujari L. Urolithiasis-an updated review over genetics, pathophysiology and its clinical management. Int J Pharm Pharm Sci 2014;6(11):23-31 